\title{
Application of mathematical modelling in evaluation of odour nuisance from selected waste management plant
}

\author{
Marcin Pawnuk ${ }^{1, *}$, and Izabela Sówka ${ }^{1}$ \\ ${ }^{1}$ Wroclaw University of Science and Technology, Faculty of Environmental Engineering, \\ pl. Grunwaldzki 9, 50-377 Wrocław, Poland
}

\begin{abstract}
A wide range of tools is required to comprehensively assess the impact of odours on people and the environment. Among them, mathematical tools for odour dispersion modelling are widely used. We can distinguish models based on Gaussian, Lagrangian and Eulerian approach. In Poland, the reference model, Operat FB, based on Gaussian way is commonly used for odour dispersion modelling. Modelling was conducted for two scenarios: first including area and point emission sources, while second one included only point sources. Comparison of both scenarios shows significant improvement of odour impact range of selected Plant in case when area sources are excluded.
\end{abstract}

\section{Introduction}

A wide range of tools is required to comprehensively assess the impact of odours on people and the environment. Effective evaluation of a specific odour emission source includes activities such as inventory of odour emission sources, determination of the sampling method, determination of odour concentration from the source, determination of emissions and odour concentrations at receptor points [1]. It is possible due to the use of a wide range of measuring tools, which include sensory methods (e.g. dynamic olfactometry), analytical methods using techniques from classical analytical chemistry and sensory-instrumental methods (e.g. electronic noses) [1-3]. The final assessment of the impact of odorous substances emitted into the atmosphere on people and the environment should be based on one of two approaches. The first is the assessment based on the characteristics of odour emission sources and prediction of concentrations at receptor points. The second approach concerns direct measurements in areas adjacent to the emission source. These approaches can be used in combination or individually [4,5]. Different types of mathematical models are used to predict odour concentrations. As shown in the published literature [6], the emission source characteristics alone is not sufficient to determine the impact of odorous pollution on humans and the environment, therefore, mathematical models are used to determine how odorous pollution spreads in the atmosphere.

\footnotetext{
* Corresponding author: marcin.pawnuk@pwr.edu.pl
} 
The purpose of the work was to characterize the available tools for modelling the dispersion of odours, together with a case study of the Polish reference model for analyses and calculations of the dispersion of odours emitted from a selected waste management plant including point and area sources.

\section{Review of models used in the odour dispersion modelling}

There are many approaches to mathematical modelling of pollutants dispersion (including odorous pollutants) in the atmosphere. Due to the mathematical basis, we can distinguish three main types of models used in pollution modelling. These models follow Gaussian, Lagrangian or Eulerian approaches.

In modelling the dispersion of odour pollution into the atmosphere, Gaussian models are considered the simplest and cheapest tools [6]. These are models based on the assumption that the spreading plume of pollution emitted from the source does not change over time (the flow is homogeneous and constant) [1,7], they are so-called stationary plume models. These are the fastest calculation models used in the atmospheric simulation of pollution transport. This is possible due to the fact that only one equation, which can be successfully calculated on most computers, is solved to compute the concentrations at the receptor points. The most important disadvantage of these models is that in stationary conditions or low wind speeds they give unfavourable results. Another critical parameter for these models is the complex topography of the area for which modelling is carried out $[6,7]$. In the case of the most advanced Gaussian models, in order to obtain the most accurate simulation results, the impact of the complex topography of the terrain and the influence of turbulence are parameterized with appropriate coefficients [7]. The Gaussian models initially served to simulate the dispersion of pollutants from point sources, however, they were quickly applied also to surface, linear and volume sources [8]. Due to limitations resulting from the fact that the plume emitted from the source as well as meteorological conditions are not variable over time, they are used for modelling average annual and hourly pollution concentrations [8]. There are many different models using the Gaussian approach to predict the concentration of odorous contaminants at receptor points. These are models such as SCREEN3, ISCST3, ISC-PRIME, TAPM, AODM. The most commonly used are AERMOD, ADMS [4, 5, 7]. Gaussian models can be used in simulating odour concentrations for a wide range of different facilities. Among them, we can distinguish waste management facilities such as landfills, wastewater treatment plants or industrial facilities.

In Poland, the Gaussian model based on the Pasquill formula is mainly used for predicting odour concentration at receptor points. It is considered as a reference model based on the guidelines contained in the Regulation of the Minister of Environment dated 26 January 2010 on reference values for some substances in the air (Journal of Laws 2010, no. 16, item 87). Pasquill's equation is as follows [9]:

$$
S_{x y z}=\frac{E_{g}}{2 \pi \bar{u} \sigma_{y} \sigma_{z}} \cdot \exp \left(-\frac{y^{2}}{2 \sigma_{y}^{2}}\right) \cdot\left\{\exp \left[-\frac{(z-H)^{2}}{2 \sigma_{z}^{2}}\right]+\exp \left[-\frac{(z+H)^{2}}{2 \sigma_{z}^{2}}\right]\right\} \cdot 1000
$$

where:

$S_{x y z}$ - concentration of the substance in the air averaged over 1 hour $\left(\mu \mathrm{g} / \mathrm{m}^{3}\right)$;

$E_{g}$ - maximum emission of gaseous substance $(\mathrm{mg} / \mathrm{s})$;

$\sigma_{y}-$ horizontal atmospheric diffusion coefficient $(\mathrm{m})$;

$\sigma_{z}-$ vertical atmospheric diffusion coefficient (m);

$\bar{u}-$ average wind velocity in the layer from the geometric height of the emitter $\mathrm{h}$ to the effective height of the emitter $\mathrm{H}(\mathrm{m} / \mathrm{s})$; 
$y$ - component of the emitter distance from the point at which the calculation is made perpendicular to the direction of the wind $(\mathrm{m})$;

$z$ - the height for which the concentration of the substance in the air is calculated (m);

In order to carry out modelling using the aforementioned model, it is necessary to collect data such as meteorological data, information on land cover, parameters of individual emitters and emissions from particular emitters [9]. This model can be used to predict the concentrations of a wide range of pollutants, including odours.

The Lagrangian models use a more complex approach than the previous model type. They are known as particle models. Forecasting the spread of pollutants in the air involves calculating the trajectory of computational particles at small time intervals in a given wind field and three-dimensional turbulence field. These particles represent a specific mass of pollutants. The dispersion of pollutants in Lagrangian models uses both stochastic (turbulence) and deterministic (wind field and buoyancy) effects. The movement of computational particles is considered to be random what makes the Lagrangian models more expensive in terms of computational costs $[6-8,10]$. Lagrangian models can be used under low wind and calm conditions [11]. There are models that can use both the Lagrangian and Gaussian approach. An example of such models are the so-called puff models. These models to represent the spread of pollutants use clouds/puffs of a defined volume. Concentrations inside puffs are driven by gaussian approach (e.g. equation (1)), while trajectories are defined by Lagrangian approach $[1,7]$. An example of such a solution is the CALPUFF tool, which was used worldwide for environmental and scientific purposes. CALPUFF model can be used to simulate odour dispersion from point, area and volume sources. To simulate odour dispersion it is necessary to obtain data such as emissions from sources, meteorological and topographical data $[11,12]$. Similar to the gaussian models, CALPUFF can be used in evaluation of odour impact range from many sources such as animal by-product utilization plants [12], landfills [13], waste and residue treatment incineration/utilization plants [14] or composting food wastes [15].

The most advanced models in terms of mathematical approach are the Eulerian models. They are known as grid models or 3-D models. These terms derive from the fact that the calculations of the dispersion of pollutants take place in a three-dimensional domain divided into specific cells / grids. Eulerian models numerically solve the dispersion equations of wind-generated turbulent flow and calculate the average concentration of pollutants in a specific 3D domain [8]. The mathematical equation is solved by means of specific initial and boundary conditions. These models allow for a better and more accurate spatio-temporal representation of simulated contaminants. Eulerian models can be used for both small scale and global scale. Pollution concentrations are calculated for individual spatial cells. They can be successfully used in unstable conditions. The biggest disadvantage of these models is that they need extremely high computer power for calculations, which generates significant costs in their use [6-8]. Mainly, these models are used to simulate dispersion of different types of pollutants in a global scale (e.g. ozone). But literature shows that they can be easily adapted to local scale use. The tool named ModOdour can be used for simulation of odour dispersion from waste landfills [8] and other waste management facilities.

\section{Evaluation of the odour impact range of the selected waste management plant using the Polish reference model}

\subsection{Plant characteristic}

The subject of the research was the Waste Management Plant located on the outskirts of a chosen city in Poland. The operations of the plant include activities related to the 
management of non-hazardous and inert waste, i.e. municipal waste. Its activity includes handling of local systems for selective waste collection, sorting and recycling of waste. The plant has its own waste sorting line. During the research time, the plant had two landfill sites. The first landfill site was closed and reclaimed, the second was under current exploitation. The exploited landfill site had the necessary systems for leachate and gases collecting. The plant does not directly border with residential development. The nearest houses are located at a distance of about 1,100 meters to the west and about 1,700 meters to the east. The plant is surrounded by a strip of greenery and is adjacent to the agricultural areas.

\subsection{Purpose and methodology of research}

In order to determine the odour impact of the Waste Management Plant, at the beginning, the odour emission sources were identified. Two types of odour emission sources have been identified: point sources and area source. The area of the landfill site being under current exploitation was identified as the area emission source. As point sources: 4 of them located above the waste reception hall and 5 directly above the sorting building were found.

The odour sampling from identified sources has been carried out in accordance with the methodology described in the PN-EN 13725:2007 "Air quality. Determination of odour concentration, with the use of dynamic olfactometry method" [16] and the VDI 3880: 2011 [17] guidelines. In the case of point sources, the sampling was carried out using a CSD30 vacuum probe, while a ventilated sampling hood was used to collect samples from the area source. In both cases, PTFE plastic bags were used. All components of the sampling kit are made of materials that do not emit or absorb odours. According to the methodology mentioned above, the bags and the remaining equipment were conditioned and cleaned before sampling. Meteorological parameters such as temperature, humidity and pressure were also measured during sampling. During the transport of samples, a constant ambient temperature was maintained to prevent potential chemical reactions that could interfere with later results.

Measurement of odour concentration was performed in the Olfactometric Laboratory. Measurements of odour concentrations have been carried out in accordance with the PN-EN 13725:2007 guidelines [16]. In determining the odour concentrations, a four-station olfactometer TO 8 with necessary equipment was used. The measurement team consisted of 5 people (4 investigators and 1 operator) which were selected in accordance with the mentioned guidelines $[16,17]$. The obtained data of the odour concentration determining tests were calculated as the geometric mean of all measurement series. The odour concentrations from tests are shown as European odour unit per cubic meter $\left(\mathrm{ou}_{\mathrm{E}} / \mathrm{m}^{3}\right)$.

\subsection{Emissions calculations and input data for modelling}

Table 1 shows the results of odour concentrations measurements and odour emission rate calculations for identified nine point and one area sources. Odour concentrations are presented as an average concentration from collected samples. Table 1 shows also necessary parameters for odour dispersion modelling, i.e.: emitter height, a diameter of the emitter (in case of area source the area of landfill site is presented in the table) and gas velocity for point sources. The temperature of emitted gases was determined at 293 Kelvin degrees.

The highest odour emission rate was obtained for the area source (E-10): 699317,0 ou $/ \mathrm{s}$. It represents emissions from landfill of area equal of 27500 square meters. Summing up the obtained emission values, the surface source can be responsible for about $99.95 \%$ of odour emission from Waste Management Plant under study. 
Table 1. Odour emission sources parameters, odour concentration measurements and estimated emission values results.

\begin{tabular}{|c|c|c|c|c|c|c|c|}
\hline 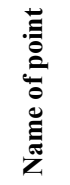 & 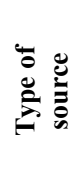 & 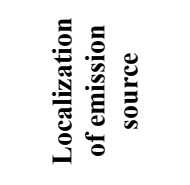 & 占 & 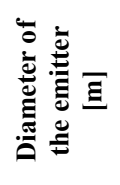 & 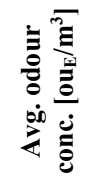 & 章 & 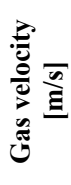 \\
\hline E-1 & point & $\begin{array}{c}\text { waste reception } \\
\text { hall } \\
\end{array}$ & 10.5 & 0.345 & 60.0 & 12.8 & 2.3 \\
\hline E-2 & point & $\begin{array}{c}\text { waste reception } \\
\text { hall }\end{array}$ & 11 & 0.345 & 60.0 & 12.8 & 2.3 \\
\hline E-3 & point & $\begin{array}{l}\text { waste reception } \\
\text { hall }\end{array}$ & 12.5 & 0.345 & 60.0 & 12.8 & 2.3 \\
\hline E-4 & point & $\begin{array}{c}\text { waste reception } \\
\text { hall }\end{array}$ & 13 & 0.345 & 60.0 & 12.8 & 2.3 \\
\hline E-5 & point & $\begin{array}{l}\text { waste sorting } \\
\text { building }\end{array}$ & 13 & 0.345 & 265.5 & 56.8 & 2.3 \\
\hline E-6 & point & $\begin{array}{l}\text { waste sorting } \\
\text { building }\end{array}$ & 11 & 0.345 & 265.5 & 56.8 & 2.3 \\
\hline E-7 & point & $\begin{array}{l}\text { waste sorting } \\
\text { building }\end{array}$ & 13 & 0.345 & 265.5 & 56.8 & 2.3 \\
\hline E-8 & point & $\begin{array}{c}\text { waste sorting } \\
\text { building }\end{array}$ & 11 & 0.345 & 265.5 & 56.8 & 2.3 \\
\hline E-9 & point & $\begin{array}{l}\text { waste sorting } \\
\text { building }\end{array}$ & 10.5 & 0.345 & 265.5 & 56.8 & 2.3 \\
\hline E-10 & area & landfill site & 3 & $\begin{array}{c}27500 \mathrm{~m}^{2} \\
\text { (landfill } \\
\text { area) }\end{array}$ & 2333.0 & 699317.0 & - \\
\hline
\end{tabular}

Obtained results were used as a input data for odour dispersion modelling from selected Waste Management Plant. Software called "Operat Fb" was used in the assessment of odour impact range. It follows Gaussian approach (equation (1)) to simulate pollution transport in the air. The software follows the guidelines contained in the Regulation of the Minister of Environment dated 26 January 2010 on reference values for some substances in the air (Journal of Laws 2010, no. 16, item 87) [9] and is considered as a reference model in pollution dispersion modelling. Table 1 shows the necessary emitter parameters used for modelling study. The aerodynamic roughness coefficient of the terrain was defined as $\mathrm{z}=0.55$. The location of the nearest residential buildings was determined (receptor points B1-B7). In accordance with the Draft law on preventing odour nuisance from 27.02.2009 (Poland) [18] the environmental detection threshold for odours pollution was established at a range of $1 \mathrm{ou}_{\mathrm{E}} / \mathrm{m}^{3}$. The maximum frequency of exceedances of the odour concentration at a level of $1 \mathrm{ou}_{\mathrm{E}} / \mathrm{m}^{3}$ was determined at $3 \%$ during the year [19]. The grid size was determined to be equal to $5800 \mathrm{~m} \times 4500 \mathrm{~m}$ with a grid step at $100 \mathrm{~m}$.

Odour dispersion modelling was carried out in two different scenarios. The first one included both point and area sources as input data for modelling, while the second scenario included only point sources. These simulations could help assess the impact odour range of selected Waste Management Plant under two different operating conditions, when the landfill is being under exploitation (first scenario) and when its closed (second scenario). According to Polish law [19], waste deposition on landfills is one of the least desirable options included in the rules of waste management handling. And therefore, the amount of operating municipal landfills should be reduced, with the intention of reducing their number to zero. As mentioned before, the Waste Management Plant activity includes not only waste deposition on landfill, so modelling in these conditions could help assess the odour impact range in the future of the Plant. 


\subsection{Results and discussion}

Figure 1 shows the maximum odour concentrations for both scenarios in a defined computational grid. Under the first scenario, the maximum odour concentration obtained from the modelling was found at point $X=2700, Y=2400$ and equals to $564.2 \mathrm{ou}_{\mathrm{E}} / \mathrm{m}^{3}$. While under the second scenario it was found at point $\mathrm{X}=2800 \mathrm{Y}=2100$ and equals to 0.2 $\mathrm{ou}_{\mathrm{E}} / \mathrm{m}^{3}$.

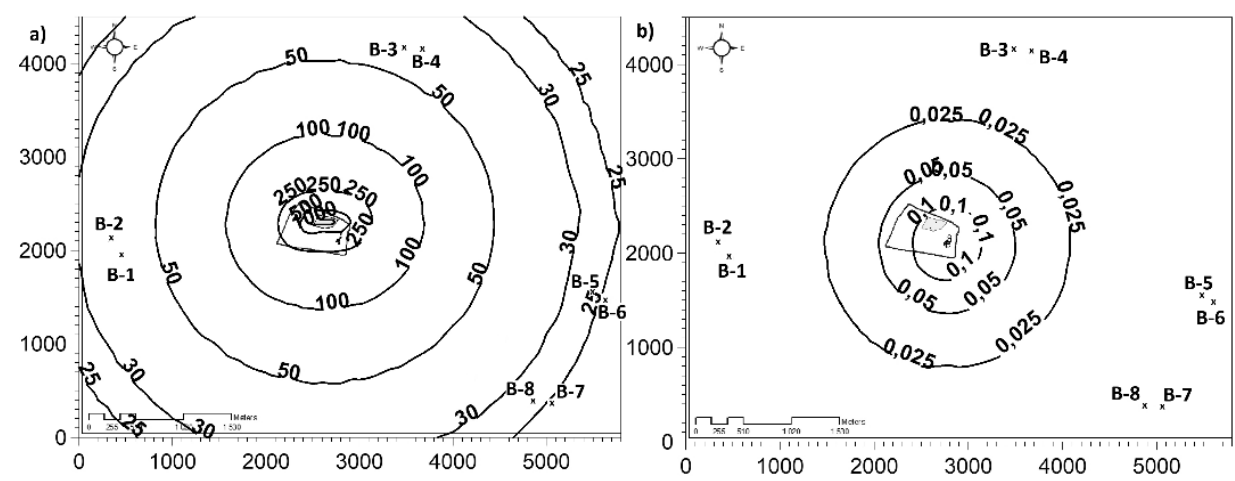

Fig. 1. The maximum odour concentrations obtained for: point and area sources (a) and point sources (b), ouE $/ \mathrm{m}^{3}$.

The frequency of exceeding the maximum odour concentration is shown in figure 2. When the point and area sources were examined together, the highest frequency of exceedances was reported at point $\mathrm{X}=2700, \mathrm{Y}=2400$ and equals to $50.9 \%$ and exceed the determined threshold level of $3 \%$ (for $1 \mathrm{ou}_{\mathrm{E}} / \mathrm{m}^{3}$ ). In the case of the second scenario, no exceedings were obtained.
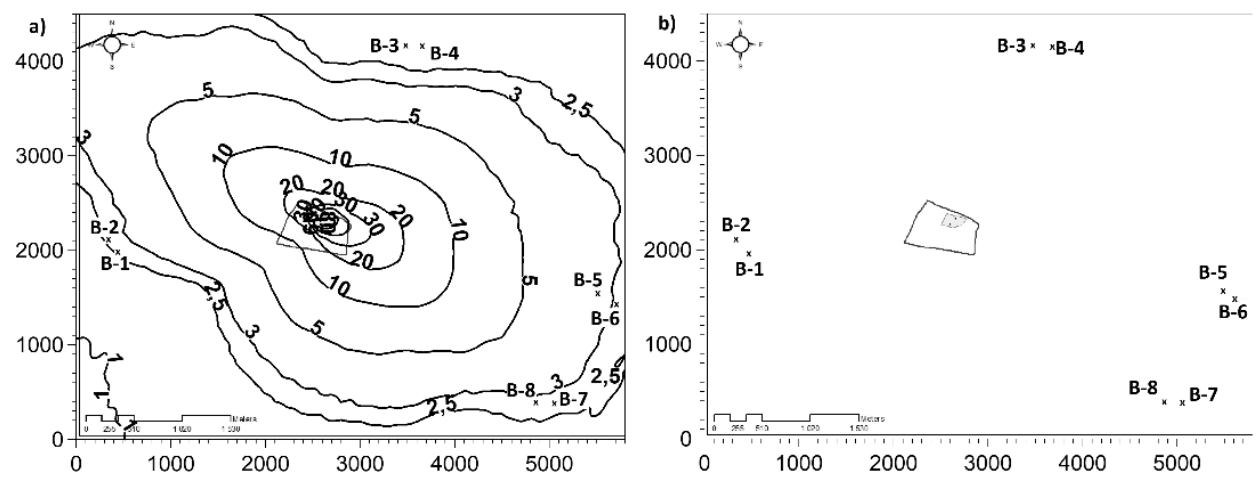

Fig. 2. The frequency of exceeding the maximum odour concentrations for: : point and area sources (a) and point sources (b), \%.

In the case of average annual odour concentration for both scenarios, the results are shown in figure 3. The highest average annual odour concentration was calculated at the same point as maximum odour concentration (first scenario) and was equal to $27.0 \mathrm{ou}_{\mathrm{E}} / \mathrm{m}^{3}$ (while the determined threshold level is at $1 \mathrm{ou}_{\mathrm{E}} / \mathrm{m}^{3}$ ). Results obtained from the second modelling does not exceed determined threshold level and the highest value equals to $0.01 \mathrm{ou}_{\mathrm{E}} / \mathrm{m}^{3}(\mathrm{X}=2800$, $\mathrm{Y}=2100)$. 

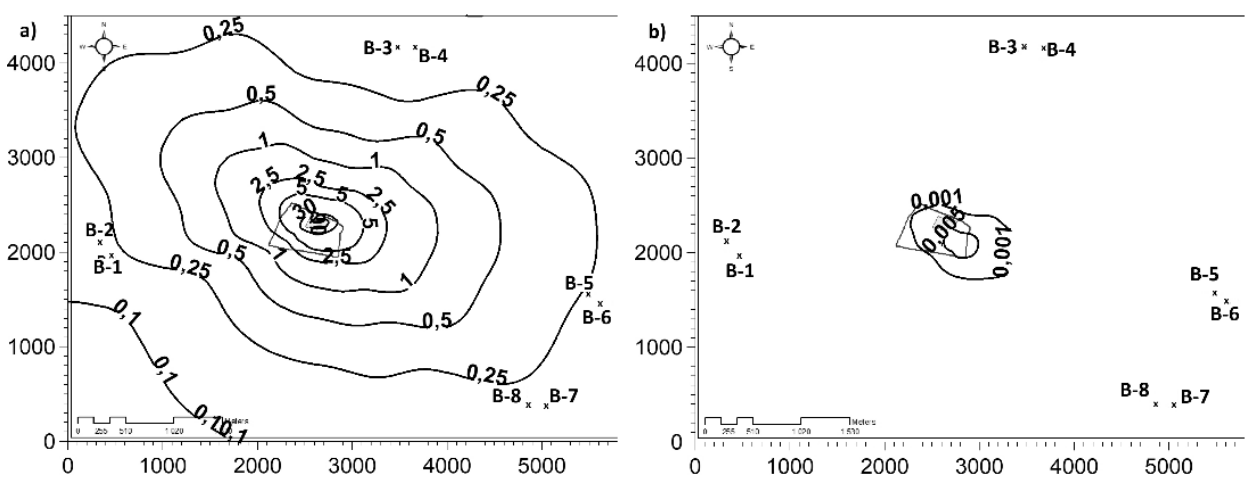

Fig. 3. The average annual odour concentrations for: : point and area sources (a) and point sources (b), ouE $/ \mathrm{m}^{3}$.

The results of the odour dispersion modelling for additional points outside the Waste Management Plant are shown in table 2. These points (B-1 to B-8) represent the nearest residential buildings. The highest maximum odour concentration for the first scenario was calculated at point B-3 $\left(40.5 \mathrm{ou}_{\mathrm{E}} / \mathrm{m}^{3}\right)$ approx. $1500 \mathrm{~m}$ from boundary of Plant. The frequency of exceedances at this point equals to $2.1 \%$. The highest frequency of exceedances for residential buildings was reported at point B-5 and equals to $3.2 \%$ of permissible threshold level of $3 \%$ per year. These values shows that the emission from the Plant could have potential impact on humans living in the neighbourhood of point B-5. The annual average odour concentration does not exceed the $1 \mathrm{ou}_{\mathrm{E}} / \mathrm{m}^{3}$ in any additional point. In case of the second scenario, there is a significant improvement of odour impact range obtained from modelling. There is no exceedances of threshold level at any points related to residential buildings, when maximum and average annual odour concentration stays at relatively low levels.

Table 2. Comparison of odour modelling for both scenarios for additional points at calculation grid.

\begin{tabular}{|c|c|c|c|c|c|c|}
\hline $\begin{array}{c}\text { Name of } \\
\text { point }\end{array}$ & $\begin{array}{c}\text { Max. odour } \\
\text { Conc. } \\
{\left[\mathbf{o u}_{\mathrm{E}} / \mathbf{m}^{3}\right]}\end{array}$ & $\begin{array}{c}\text { Annual } \\
\text { Avg. Conc. } \\
{\left[\mathbf{o u}_{\mathrm{E}} / \mathbf{m}^{3}\right]}\end{array}$ & $\begin{array}{c}\text { Freq. of. } \\
\text { exc. [\%] }\end{array}$ & $\begin{array}{c}\text { Max. } \\
\text { odour } \\
\text { Conc. } \\
{\left[\mathbf{o u}_{\mathrm{E}} / \mathbf{m}^{3}\right]}\end{array}$ & $\begin{array}{c}\text { Annual } \\
\text { Avg. Conc. } \\
{\left[\mathbf{o u}_{\mathrm{E}} / \mathbf{m}^{3}\right]}\end{array}$ & $\begin{array}{c}\text { Freq. of. } \\
\text { exc. [\%] }\end{array}$ \\
\hline- & \multicolumn{3}{|c|}{ First scenario } & \multicolumn{3}{|c|}{ Second scenario } \\
\hline B-1 & 38.5 & 0.2 & 2.5 & 0.0 & 0.0 & 0.0 \\
\hline B-2 & 36.6 & 0.2 & 2.6 & 0.0 & 0.0 & 0.0 \\
\hline B-3 & 40.5 & 0.1 & 2.1 & 0.0 & 0.0 & 0.0 \\
\hline B-4 & 39.7 & 0.1 & 1.9 & 0.0 & 0.0 & 0.0 \\
\hline B-5 & 26.2 & 0.2 & 3.2 & 0.0 & 0.0 & 0.0 \\
\hline B-6 & 25.1 & 0.2 & 2.9 & 0.0 & 0.0 & 0.0 \\
\hline B-7 & 24.6 & 0.2 & 2.8 & 0.0 & 0.0 & 0.0 \\
\hline B-8 & 26.3 & 0.2 & 2.9 & 0.0 & 0.0 & 0.0 \\
\hline
\end{tabular}

\section{Summary and conclusion}

Many of different tools can be used in odour dispersion modelling, for example, Gaussian, Lagrangian and Eulerian models. Among them, Polish reference model "Operat Fb" that follows Gaussian approach, can be distinguished as one of the useful tools for predicting odour concentration at receptor network, especially under averaged meteorological parameters and for area and point sources. In this paperwork, with help of the polish reference model it was possible to obtain valid data about the odour impact range from selected Waste Management Plant under two different scenarios. Obtained results for the first scenario shows that the odour impact range of selected Plant is significant. The Plant could have potential 
impact on humans and environment. The exceeding of permissible threshold level occurs at residential area, approx. $2100 \mathrm{~m}$ from plant boundary. Therefore, it is necessary to take certain actions aimed at reducing the influence of the odour impact of selected Waste Management Plant. In the case of the second scenario the odour impact range is significantly lower, results did not show any impact near residential buildings. No actions are needed. The conducted research shows that the most of odour emission comes from landfill site and it is responsible for almost all the odour nuisance caused by the Plant. Closing the landfill site could improve the air quality near the Plant. The research shows that polish reference model "Operat Fb" could be used as a valid tools in odour impact assessment.

\section{European} Funds

Knowledge Education Development

\section{European Union}

European Social Fund

\section{References}

1. T. Kiełbasa, P. Sobczyński, M. Skrętowicz, I. Sówka, Mathematical tools in odour impact assessment of the municipal facilities (Oficyna Wydawnicza Politechniki Wrocławskiej, Wrocław, 2013) (in Polish)

2. R. Barczak, Comparative Analysis of Field Olfactometry with Other Research Methods in the Odour Impact Assessment of Wastewater Treatment Plants ( $\mathrm{PhD}$ dissertation, 2014) (in Polish)

3. J. Gębicki, H. Bylinski, J. Namieśnik, Environ. Monit. Assess. 188, 1 (2016)

4. I. Sówka, Methods of identification of odour gases emitted from industrial plants (Oficyna Wydawnicza Politechniki Wrocławskiej, Wrocław, 2011) (in Polish)

5. A. J. Nicell, Atm. Env. 43 (2009)

6. L. Capelli, S. Sironi, R. Del Rosso, J. M. Guillot, Atm. Env. 73 (2013)

7. A. Leelossy, F. Molnár, F. Izsák, A. Havasi, I. Lagzi. R. Mészáros, Cent. Eur. J. Geosci. 6, 3 (2014)

8. L. Yanjun, Z. Yan, L. Wenjing, W. Hongtao, H. Qifei, Env. Mod. \& Soft. 113 (2019)

9. Regulation of the Minister of Environment dated 26 January 2010 on reference values for some substances in the air. (Journal of Laws 2010, no. 16, item 87)

10. J. Nielinger, R. Röckle, H. C. Hölf, W. J Kost Lagrange versus Eulerian dispersion modeling comprasion for investigations concerning air pollution caused by traffic (2004)

11. L. Capelli, S. Sironi, Atm. Env. 191 (2018)

12. S. Sironi, L. Capelli, P. Centola, R. Del Rosso, S. Pierucci, Atm. Env. 44 (2010)

13. J. Badach, P. Kolasińska, M. Paciorek, W. Wojnowski, T. Dymerski, J. Gębicki, M. Dymnicka, J. Namieśnik, J. Environ. Manage. 213 (2018)

14. S. C. Doğruparmak, H. Pekey, D. Arslanbaş, Env. For. 19, 1 (2018)

15. L. Dentoni, L. Capelli, S. Sironi, J.M. Guillot, Water. Sci. Technol. 68, 8 (2013)

16. PN-EN 13725:2007: Air quality. Determination of odour concentration, with the use of dynamic olfactometry method

17. VDI 3883: Olfactometry. Static sampling (Verein Deutscher Ingenieure, 2011)

18. Waste management Act dated 14 December 2012 (Journal of Laws 2013, item 21)

19. The Draft law on preventing odour nuisance from 27.02.2009 (Poland) 